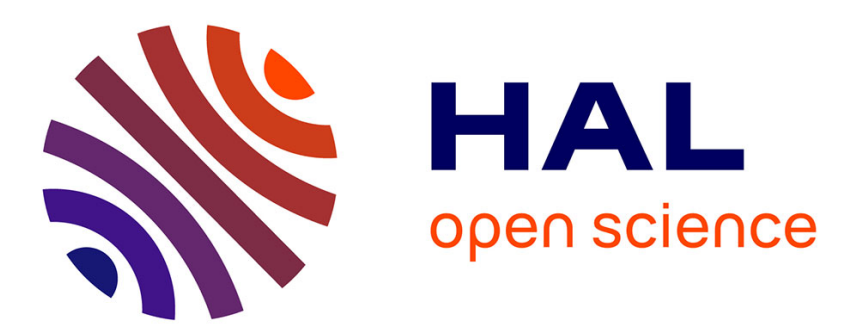

\title{
Certification for trace elements and methyl mercury mass fractions in IAEA-452 scallop (Pecten maximus) sample
}

E. Vasileva, Sabine Azemard, Jae Oh, Paco Bustamante, Maria Betti

\section{- To cite this version:}

E. Vasileva, Sabine Azemard, Jae Oh, Paco Bustamante, Maria Betti. Certification for trace elements and methyl mercury mass fractions in IAEA-452 scallop (Pecten maximus) sample. Accreditation and Quality Assurance, 2011, 16, pp.439-447. 10.1007/s00769-011-0793-y . hal-00784155

\section{HAL Id: hal-00784155 \\ https://hal.science/hal-00784155}

Submitted on 3 Feb 2013

HAL is a multi-disciplinary open access archive for the deposit and dissemination of scientific research documents, whether they are published or not. The documents may come from teaching and research institutions in France or abroad, or from public or private research centers.
L'archive ouverte pluridisciplinaire HAL, est destinée au dépôt et à la diffusion de documents scientifiques de niveau recherche, publiés ou non, émanant des établissements d'enseignement et de recherche français ou étrangers, des laboratoires publics ou privés. 
Certification for trace elements and methyl mercury mass fractions in IAEA-452 scallop (Pecten Maximus) sample

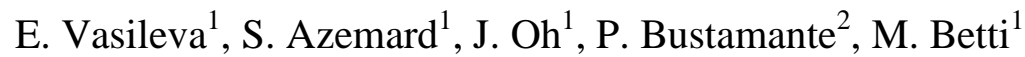

1- International Atomic Energy Agency, Environment Laboratories, 4 Quai Antoine 1er, Principality of Monaco, Monaco 98000, Monaco

e-mail: e.vasileva-veleva@iaea.org

2- Littoral, Environnement et Sociétés (LIENSs), UMR 6250 CNRS-Université de La Rochelle, 2 rue Olympe de Gouges, 17042 La Rochelle, France

\begin{abstract}
A marine certified reference material (CRM), IAEA-452, prepared with scallop (Pecten maximus) sample was recently produced by the International Atomic Energy Agency (IAEA) and certified for trace elements and methyl mercury (MeHg). The Scallop (Pecten maximus) sample is commonly found and consumed seafood and is also used as bio-indicators for trace metal contamination in marine pollution studies. This paper presents the sample preparation methodology, material homogeneity and stability studies, evaluation of certification campaign results, the assignment of property values and their associated uncertainty. The reference values and associated expanded uncertainty for 9 trace elements ( $\mathrm{As}, \mathrm{Cd}, \mathrm{Cr}, \mathrm{Cu}, \mathrm{Fe}, \mathrm{Hg}, \mathrm{Mn}, \mathrm{Pb}$ and $\mathrm{Zn}$ ) and $\mathrm{MeHg}$ in scallop sample are established. The informative value for one more element $(\mathrm{Ni})$ is also given. The new CRM can be used for the development and validation of analytical methods for determination of trace elements and methyl mercury in seafood and also for quality assurance/quality control purposes.
\end{abstract}

Keywords: Trace elements; Methyl mercury; Marine biota sample, CRM; Seafood safety; Certification

\title{
Introduction
}

Society's growing interest in environmental issues requires the production of reliable information for policy-makers, stakeholders and society in general. This information must be based on accurate and comparable results produced by qualified laboratories. National and international marine monitoring programmes have been initiated worldwide to assess the quality of the marine environment. In monitoring programme, it is considered essential to 
ensure that the data produced from different laboratories over a number of years can be compared. If results are to be comparable, it is essential that they are based on reliable measurement standards whose values are linked to a stated reference. The difficulties inherent to traceability are generally recognised, but this task can be considerably simplified by the use of a suitable CRM. CRMs are key tools to establish traceability of measurement results. Indeed, the best reference material should be of a matrix similar to the analysed sample and should contain comparable mass fraction of analytes of interest. Regular use of CRM by laboratories is essential also for the performance evaluation of analytical techniques and for the validation of analytical methods used in environmental monitoring programmes.

The Marine Environmental Studies Laboratory (MESL) of the IAES's Environment Laboratories (IAEA-EL) has the programmatic responsibility to provide assistance to Member State laboratories in maintaining and improving the reliability of analytical measurement results, both in trace elements and organic pollutants. This is accomplished through the provision of CRMs of marine origin, validated analytical procedures, training in the implementation of internal quality control and through the evaluation of measurement performance by the organization of worldwide and regional interlaboratory comparison exercises. IAEA's Analytical Quality Control Service (AQCS), now named Reference Products for Environment and Trades represents important bench mark in upgrading the quality of laboratory performances and assessing the validity of the analytical methods used for marine monitoring studies in the Member States.

One of the outcomes from the IAEA Coordinated Research Project on seafood safety was the identification of the need of producing seafood matrix CRM with elevated level of toxic elements. The species selected was scallop (Pecten maximus), which is popular seafood in many countries and is used to assess the potential transfer of toxic elements through the food chain.

The CRM IAEA-452 will assist laboratories in validating their analytical methods and controlling the quality of produced analytical results for the determination of trace elements and methyl mercury in marine biota samples.

\section{Methodology}

\section{Collection and preparation of the material}


A $200 \mathrm{~kg}$ of Scallop (Pecten maximus) was collected in December 2007 and January 2008 by scuba diving in the 'Pertuis Breton', Western France. Organisms were immediately dissected. Soft tissues (the gills, mantle and digestive glands) were thawed overnight in a refrigerator and lyophilised in a Labconco Freeze Dry System 4.5 (Labconco, Kansas City, USA). The freeze dried matter was milled to a powder in a grinder Retsch SM 200 (Retsch, Haan, Germany). The powder was then sieved through a $250 \mu \mathrm{m}$ sieved (Fritsch, Idar Oberstein, Germany). Biota particles retained in the sieve were collected, milled and sieved again. The sieved material with a particle size of less than $250 \mu \mathrm{m}$ was further homogenized. The homogeneity was performed by mixing the material in a stainless steel rotating homogeniser Moritz ERM-BB124 (Moritz, Chatou, France) for 14 days in a clean atmosphere at a temperature of $(20 \pm 2)^{\circ} \mathrm{C}$ and relative humidity of $50 \%$. After checking for the homogeneity of sample material, aliquots of about $8 \mathrm{~g}$ were packed into pre-cleaned brown borosilicate glass bottles with polyethylene screw caps and then sealed in plastic bags. The sample material was labeled as IAEA-452 sample. The average moisture content of the sample after bottling was determined by drying to a constant weight at $105^{\circ} \mathrm{C}$.

\section{Selection of laboratories for the certification campaign}

The selection of participants for this certification exercise was based on the measurement performances, demonstrated by laboratories in the previous IAEA interlaboratory comparisons. Each laboratory received one bottle of scallop (Pecten maximus) sample, accompanied by an information sheet and a report form. Participants were requested to analyse as many trace elements as possible, using a validated analytical method. They were asked to report the measurement results (six replicates and average value) along with the expanded uncertainty in addition to the information about the applied quality control procedure. The second request was to report results for the trace elements in CRM with similar to the candidate reference material matrix. Moisture determination method was prescribed.

Sixteen from 23 invited laboratories sent the requested information-measurement result (value and expanded uncertainty), description of the method used, results from the analysis of CRM and result for moisture determination.

The reference value for $\mathrm{MeHg}$ was obtained from the results of the worldwide interlaboratory comparison run on the same matrix in 2009 [1].

List of laboratories participating in the certification exercise is presented in Table 1. 


\section{Homogeneity testing}

Extensive homogeneity tests were carried out on this material in order to ensure its suitability as a candidate reference material and to estimate the uncertainty associated with homogeneity of the sample.

Between-bottles homogeneity was tested by the determination of the mass fraction of some typical elements (As, $\mathrm{Cd}, \mathrm{Cr}, \mathrm{Cu}, \mathrm{Fe}, \mathrm{Hg}, \mathrm{Mn}, \mathrm{Ni}, \mathrm{Pb}, \mathrm{Zn}$ and $\mathrm{MeHg}$ ). Totally, 10 bottles were selected using random stratified sampling of the whole batch. Care was taken to ensure that the order of measurements did not correspond to the filling sequence of the bottles, which enable the differentiation between potential trend in the filling sequence and analytical drift. Three subsamples from each bottle were analysed for their total element mass fractions.

The within-bottle homogeneity was assessed by 15

replicate determinations of the content of investigated trace elements in one bottle. Subsamples of $0.2 \mathrm{~g}$ were mineralized with $5 \mathrm{~mL}$ conc. HNO3 and digested in a microwave oven by adding $2 \mathrm{~mL}$ conc. HF according to the protocol described earlier [1]. The final measurements were performed by graphite furnace atomic absorption spectrometry under repeatability conditions and in a randomised way in order to be able to separate a potential analytical drift from a trend in the filling sequence. The determination of the total mercury was done in solid subsamples with solid mercury analyser. The method used for homogeneity study of MeHg was based on alkaline digestion and aqueous phase ethylation followed by gas chromatography separation, thermal desorption of $\mathrm{Hg}$ species and atomic fluorescence spectrometry (AFS) detection. All methods used for homogeneity studies were previously validated in MESL, IAEA.

\section{Stability study}

Three sets of five bottles each were stored in the dark at different temperature, $-20{ }^{\circ} \mathrm{C},+20$ and $+60{ }^{\circ} \mathrm{C}$, just after bottling process and kept at described conditions over a period of 2 years. One isochronous study over 8 weeks was applied to evaluate stability of the materials during transport and one isochronous study over 12 and 24 months, respectively, to evaluate stability during storage. Obtained results were compared with the results from samples kept at $-20{ }^{\circ} \mathrm{C}$ during this period $\left(-20{ }^{\circ} \mathrm{C}\right.$ is considered as reference temperature). The stability investigation for the evaluation of long-term stability is still on-going. 


\section{Characterisation}

Characterisation refers to the process of determining the reference values. The candidate reference material was initially analysed at the IAEA-EL in Monaco. The final characterisation was based on the results delivered by selected laboratories with demonstrated measurement capabilities, based on criteria that comprised both technical and quality management aspects. Characterisation of the trace element mass fraction in IAEA-452 scallop (Pecten maximus) sample was based on the application of different analytical techniques as summarised on Fig. 1. All participating laboratories have used validated methods for determination of trace elements in marine samples. In addition, they provided results from the analysed CRM with similar matrix composition and the information on standard calibration solutions, used for every trace metal and $\mathrm{MeHg}$. The results of laboratories that did not report any quality assurance information were excluded from the further evaluation.

Combined uncertainties were calculated in compliance with the guide to the expression of uncertainty in measurement (GUM) [3], including uncertainties due to possible heterogeneity and instability.

All participating laboratories claimed traceability of provided results to the international system of units (SI) via standard calibration solutions and CRM applied as a part of their analytical procedures.

\section{Moisture determination}

The determination of the moisture content of the samples is to some extent 'operationally defined'. In view of the comparability of results, the protocol for the correction of the moisture was developed at IAEA-EL and prescribed to other participants. The drying procedure at $\left(85^{\circ} \pm 2\right)^{\circ} \mathrm{C}$ was established after experimental evaluation of sample stability. Correction for dry mass was obtained from separate portions of the material of minimum mass of $0.5 \mathrm{~g}$ (10 sub-samples from 5 bottles). The weighing and repeated drying were performed until constant mass was attained. Moisture determined at $85^{\circ} \mathrm{C}$ was found to be $6.5 \% \pm 0.4 \%$ for bottles kept at $20{ }^{\circ} \mathrm{C}$.

\section{Results and discussion}

Results from the homogeneity study 
For the homogeneity study, 10 samples (about $2.0 \%$ of the total batch) of IAEA-452 were chosen using a random stratified sample picking scheme and analysed for their trace elements and $\mathrm{MeHg}$ contents in triplicate. The results were combined and evaluated to detect any trends regarding filling or analysis sequence and to estimate the uncertainty contribution from possible heterogeneity. Grubbs tests were performed to identify potentially outlying individual results as well as outlying bottles means. Two individual results for $\mathrm{Ni}, \mathrm{Cr}$ and $\mathrm{Pb}$, respectively, were detected as outlier. These results were excluded as they were outliers at $95 \%$ but also at $99 \%$ confidence level.

The retained individual results and bottle means were checked whether they follow a normal distribution or are unimodally distributed. The series of results for investigated trace elements and $\mathrm{MeHg}$ were normally distributed. The distribution for $\mathrm{Cr}, \mathrm{Ni}$ and $\mathrm{Pb}$ was skewed, but unimodal. One-way analysis of variance (ANOVA) [2] was then applied to assess betweenbottles and within-bottles homogeneities. The ANOVA allowed the calculation of within unit standard deviation $s_{w b}$ and also between bottles standard deviation $s_{b b}$ :

$$
\begin{aligned}
& s_{\mathrm{wb}}=u_{w b}=\sqrt{M S_{w b}} \\
& s_{b b}=u_{b b}=\sqrt{\frac{M S_{b b}-M S_{w b}}{n}}
\end{aligned}
$$

For several elements (As, Fe, $\mathrm{Zn}, \mathrm{MeHg}$ ), $M S_{b b}$ (ANOVA mean square between bottles) was smaller than $M S_{w b}$ (ANOVA mean square within bottles) and $S_{b b}$ could not be calculated. Instead $u_{b b}^{*}$, the heterogeneity that can be hidden by the method repeatability was calculated, as described by Linsinger et al. [4]:

$$
u_{b b}^{*}=\frac{s_{w b}}{\sqrt{n}} \sqrt[4]{\frac{2}{v_{M S w b}}}
$$

where ' $\mathrm{n}$ ' is number of replicate sub-samples per bottle and $v M S_{w b}$ is the degrees of freedom of $M S_{w b}$.

Heterogeneity could be quantified due to the good repeatability of the method used. The between-bottles variations/heterogeneity was between 2.0 and $6.1 \%$, small enough to ensure 
the homogeneity of the material. The uncertainty contributions due to the inhomogeneity were estimated according to ISO Guide 35 [2] as the maximum values obtained with Eq. 2 or Eq. 3. The results for sample size $0.2 \mathrm{~g}$ are presented in Table 2 . The conclusion from the presented results for the tested trace elements was that the homogeneity of the candidate reference material complied with the provisions given by the ISO 35 at the range of weights used. A minimum sample intake of $0.2 \mathrm{~g}$ was set, based on the smallest sample intake used in the characterisation study.

\section{Results from the stability study}

Samples selected for stability study were analysed and each of the elements was evaluated individually. No outliers were detected on $95 \%$ confidence level in any study. The evaluation of data was further carried out by performing a linear regression on the determined mass fractions versus time.

The test material showed no significant trend to degradation over the time frame at different temperature $-20,+20$ and $+60{ }^{\circ} \mathrm{C}$. Significant impact of storage conditions on the stability of the certified properties could not be detected, neither of storage time nor of temperature (up to $+60{ }^{\circ} \mathrm{C}$ ). In all cases, the slope of the linear regression did not significantly differ from zero. No significant slope at $95 \%$ level of confidence was detected for any of investigated analytes, neither in the short-term study nor in the long-term study. As no degradation could be observed under any conditions, neither in the short-term nor in the long-term study, it was concluded that no special precautions regarding temperature control during shipment are necessary. The uncertainty of the short-term stability $\left(u_{s t s}\right)$ was assumed to be negligible since no degradation is expected to happen during this short time. Nevertheless, $-20{ }^{\circ} \mathrm{C}$ was chosen as storage temperature.

Failure to detect degradation does, however, not prove stability. The uncertainty of stability $u_{\text {stab }}$ describes the potential degradation which still can be reconciled with the data, even if the slope is not statistically significantly different from zero. Although under these conditions, an expansion of the total uncertainty of the certified values is generally not encouraged, in this case the approach of ISO Guide 35 was followed, mainly due to the lack of sound alternatives. An uncertainty contribution related with stability of the candidate reference material was estimated as uncertainty of the regression line with a slope of 0 multiplied with the chosen shelf life, as described by Linsinger et al. [5]. Factor of 3 was selected, taking into 
account a minimum shelf life of 3 years. Stability during storage period was chosen $1 \%$, which ensured the validity of the certificate for at least 3 years. Results for $\mathrm{MeHg}$ mass fractions in IAEA-452 scallop (Pecten maximus) sample found in bottles kept at different storage conditions over 3-year period are presented in Table 3. Each result is obtained as a mean value for $\mathrm{MeHg}$ mass fractions for three different bottles (tree replicates from each one). Obtained results from short-term and long-term studies provide evidence for a good stability of all analytes under consideration, including $\mathrm{MeHg}$.

\section{Determination of certified values and uncertainties}

The characterisation campaign resulted in 7-14 results per element and 16 results for $\mathrm{MeHg}$. The obtained data were first checked for compliance with the certification requirements and then for their validity based on technical reasons. All accepted set of results were submitted to the following statistical tests: Grubbs test to detect single and double outliers, Dixon's test to detect outlying lab means and Kolmogorov-Smirnov test for normal distribution.

Four outlying values (two for $\mathrm{Zn}$, one for $\mathrm{Cr}$ and one for $\mathrm{Cu}$ ) were detected in the received data sets. These results were outliers at $95 \%$, but not at $99 \%$ confidence level. The outlying values were scrutinised but no technical reason for exclusion was found. Therefore, results were accepted for further evaluation. The normal distribution at $95 \%$ level of confidence was found for the sample means of all studied elements except for $\mathrm{Zn}$. At $99 \%$ level of confidence, Zn means were also normally distributed. All laboratories reported combined standard and expanded uncertainties. As more important contributors to the combined uncertainty they stated recovery, within lab reproducibility and uncertainty of the reference value of the used CRM.

The application of robust statistics as it is described in ISO 13528 [5] is IAEA-452 reference values were calculated as a median of the accepted dataset, rounded off to the most significant number of the uncertainty. The robust mean and unweighted mean of the means were also calculated and compared with the respective medians. As no differences were observed, the reference values obtained with the median approach were further used. These values are considered to be the most reliable estimates of the property values.

The uncertainties associated with the reference values were calculated according to the ISO Guide 35 [2]. The relative combined uncertainty of the certified value of the CRM consists of uncertainty related to characterization $u_{c h a r}$, between bottle heterogeneity $\left(u_{b b}\right)$ and long-term 
stability $\left(u_{s t a b}\right)$. These different contributions were combined to estimate the expanded, relative uncertainty.

$U_{C R M, r e l}^{2}=4\left(u_{\text {char }}^{2}+u^{2}{ }_{h o m}+u_{\text {stab }}^{2}\right)$

where $k$ coverage factor equalling 2, representing a level of confidence of about $95 \%$. $u_{\text {hom }}$ was estimated as a larger value of the standard deviation between bottles $\left(u_{b b}\right)$ or the maximum heterogeneity potentially hidden by the method repeatability $\left(u_{b b} *\right)$ as shown on the Table 2. $u_{\text {stab }}$ is stability during storage period was chosen as $1 \%$, which as described before, ensured the validity of the certificate for at least 3 years.

$u_{\text {char }}$ was estimated using an approach described by Pauwels et al. [6]. In this approach, the uncertainty of characterisation is separated into laboratory-dependent uncertainty $u(\mathrm{I})$, uncertainty common to all laboratories $u$ (II) and uncertainty common to a groups of laboratories $u(\mathrm{III})$.

$$
u(\mathrm{I})=\frac{\sqrt{u_{i}^{2}}}{n}
$$

where $u_{i}$ is the combined standard uncertainty for the mean value given by each laboratory and $\mathrm{n}$ is the number of laboratories. For this study, $u(\mathrm{II})$ and $u$ (III) were set to zero.

As it can be seen from the Fig. 1, methods with different measurement principles (AAS, GFAAS, AFS, ICP-OES, ICP-MS) as well as methods without sample preparation step (NAA) were used for characterisation of the material. The agreement between results confirms the absence of any significant method bias and demonstrates the identity of the analyte. Provided by participants results for trace elements and $\mathrm{MeHg}$ mass fractions grouped by methods are displayed in Figs. 2, 3, 4, 5, 6, 7, 8, 9, 10, 11. In all figures, the reported results are plotted versus the reference values, which are denoted by a bold line, while the dashed lines represent the expanded uncertainty $(k=2)$ associated with the reference value. Error bars represent expanded uncertainty as reported by participants. A good agreement within the stated uncertainty was observed for results obtained with different methods. Therefore, all of them were considered in the deriving of reference values. 
The reference values for the $\mathrm{As}, \mathrm{Cd}, \mathrm{Cr}, \mathrm{Cu}, \mathrm{Fe}, \mathrm{Hg}, \mathrm{Mn}, \mathrm{Pb}, \mathrm{Zn}$ and $\mathrm{MeHg}$ are presented in Table 4, together with their expanded uncertainty $(k=2)$. Due to the limited number of provided results, Information value was assigned to $\mathrm{Ni}-$ Fig. 12.

\section{Methyl mercury $(\mathrm{MeHg})$ certification}

In total, 16 laboratories sent results for $\mathrm{MeHg}$ in the frame of IAEA-452 interlaboratory comparison [1]. The 16 results for $\mathrm{MeHg}$ were obtained using a variety of methodologies as described in Table 5. In the first step-release of $\mathrm{MeHg}$ from the binding sites-three techniques were mainly used: distillation, alkaline digestion and acid leaching. Further steps included separation of organic and inorganic mercury by ion-exchange, solvent extraction or gas chromatography after appropriate derivatisation. The following methods were then applied for the detection of $\mathrm{MeHg}$ : Atomic fluorescence spectrometry, gas chromatography with electron capture detector, inductively coupled plasma mass spectrometry and cold vapour-atomic absorption spectrometry. Two laboratories used species-specific isotope dilution inductively coupled plasma mass spectrometry (ID-ICP-MS).

ID-ICP-MS method is considered as potentially primary method of measurement and gives the results with highest metrological quality. As it can be seen from Fig. 11, the results within uncertainty obtained with other methods are in good agreement with those obtained after application of species-specific ID-ICP-MS. Therefore, the reference value for $\mathrm{MeHg}$ in IAEA-452 sample was calculated taking into account the results provided by all 16 laboratories participating in the IAEA interlaboratory comparison study.

\section{Metrological traceability and commutability}

If results obtained by different laboratories are to be comparable, it is essential that all results are based on reliable measurement standards whose values are linked to a stated reference.

Only validated methods applied within stated scope were used by participating in the certification exercise laboratories. Matrix CRMs with stated SI traceability purchased from NIST, EC JRC IRMM, NRC-CNRC were used for validation of the applied in this study methods [1].

Pure metal standard solutions (CRM) with stated purity were employed for calibration from all laboratories participating in the certification campaign. As stated in the respective certificates of all CRM producers, the mass fractions of the trace element and $\mathrm{MeHg}$ in the 
respective standard solutions were measured against another CRM (i.e. NIST, BAM or EMPA) with demonstrated SI traceability followed by gravimetric preparation using balances calibrated with SI-traceable weights. Consequently, the value calculated by this unbroken chain of comparison is traceable to the reference to which the starting material is compared.

In addition, the agreement between the results confirms absence of any significant method bias and demonstrates the identity of the analytes.

Commutable CRMs should exhibit a similar analytical behaviour for given method as a real laboratory sample. Characterisation study has been selected such as to provide variety of analytical methods, regarding sample preparation, calibration and detection. The good agreement between the results obtained indicates commutability of the material. However, CRMs might show behaviour different from that of real samples, in particular during digestion, due to their small particle size in contrast to the possible larger particle size for real laboratory samples. The commutability was also confirmed in the frame of the IAEA worldwide inter-laboratory comparison for trace elements with the same sample material, where 143 laboratories took part [1].

\section{Conclusion}

This exercise allows assignment of reference values for $\mathrm{As}, \mathrm{Cd}, \mathrm{Cr}, \mathrm{Cu} \mathrm{Fe}, \mathrm{Hg}, \mathrm{Mn}, \mathrm{Pb}, \mathrm{Zn}$ and $\mathrm{MeHg}$ with associated uncertainties following ISO guidelines. The certified values are derived from measurement results provided by the laboratories participating in the certification campaign. Only validated methods were applied in the certification of IAEA-452 scallop (Pecten maximus) sample. As the certified values are combinations of SI-traceable individual results, they are themselves traceable to SI. The obtained results are in excellent agreement with the results from IAEA-452 worldwide inter-laboratory comparison exercise.

The produced matrix CRM is suitable for quality control purposes of environment and food laboratories and has a high-level $\mathrm{Cd}$ as requested by experts in food safety. As any certified reference material, it can be used for validation studies.

\section{Acknowledgments}

The authors wish to acknowledge laboratories participating in IAEA-452 certification study. The Agency is grateful for the support provided to its Environment Laboratories by the Government of the Principality of Monaco. This work was supported by the UNEP MEDPOL Programme. 


\section{References}

1. Vasileva E, Azemard S, Oh J (2010) World-wide intercomparison exercise for the determination of trace elements and methyl mercury in IAEA-452 Biota sample, IAEA/192, 2011

2. ISO Guide 35 (2006) Reference materials-general and statistical principles for certification. International Organisation for Standardization, Geneva

3. ISO Guide to the expression of uncertainty of measurements (1995) International Organisation for Standardization: Geneva

4. Linsinger T, Pauwels J, Van der Veen A, Schimmel H, Lamberty A (2005) Accred Qual Assur 6:20-25

5. ISO Guide 13528 (2005) Statistics methods for use in proficiency testing by interlaboratory comparisons. International Organisation for Standardization, Geneva

6. Pauwels J, Lamberty A, Schimmel H (1998) Accred Qual Assur 3:180-181 
Table 1. List of laboratories participating in IAEA-452 certification campaign

\begin{tabular}{ll}
\hline Laboratories & Country \\
\hline International Atomic Energy Agency, IAEA & UN \\
Brooks Rand Labs BRL & USA \\
University of Plymouth, UP & UK \\
Finnish Customs Laboratory, FCL & Finland \\
Centro de Energia Nuclear na Agricultura, CENA & Brazil \\
Comisión Chilena de Energía Nuclear, CCEN & Chile \\
Institute for Environmental Protection and Research, ISPRA & Italy \\
Laboratory of Environmental Chemistry, NKUA & Greece \\
Flett Research Ltd., FRLtd & Canada \\
Ukranian Scientific Center of the Ecology of the Sea, UkSCES & Ukraine \\
Trent university, TU & Canada \\
Laboratory of Public Health, Department of Health, LPH & Macao \\
National Agency for New Technologies, Energy and Sustainable & Italy \\
Economic Development, ENEA & \\
Institute of Nuclear Chemistry and Technology, INCT & Poland \\
Israel Oceanographic \& Limnological Research, IO-LR & Israel \\
Institute of Public Health, IPH & Croatia \\
\hline
\end{tabular}


Table 2. The estimate of inhomogeneity contributions to the total uncertainty for the certified trace elements

\begin{tabular}{llllllllllll}
\hline Element & $\mathrm{As}$ & $\mathrm{Cd}$ & $\mathrm{Cr}$ & $\mathrm{Cu}$ & $\mathrm{Fe}$ & $\mathrm{Hg}$ & $\mathrm{Mn}$ & $\mathrm{Ni}$ & $\mathrm{Pb}$ & $\mathrm{Zn}$ & $\mathrm{CH}_{3} \mathrm{Hg}$ \\
\hline$u_{\mathrm{bb}}(\%)$ & & 2.3 & 6.1 & 1.2 & & 1.2 & 1.8 & 4.5 & 5.9 & & \\
$u_{b b}^{*}(\%)$ & 2.2 & & & & 1.6 & & & & & 0.9 & 3.2 \\
\hline
\end{tabular}


Table 3. Mass fractions in mg kg-1 of MeHg in IAEA-452 scallop (Pecten Maximus) sample found in bottles kept for different time at different storage conditions

\begin{tabular}{llll}
\hline Temperature & $-20{ }^{\circ} \mathrm{C}$ & $20{ }^{\circ} \mathrm{C}$ & $60{ }^{\circ} \mathrm{C}$ \\
\hline 1 week & $0.022 \pm 0.03$ & $0.023 \pm 0.04$ & $0.021 \pm 0.04$ \\
1 year & $0.021 \pm 0.02$ & $0.020 \pm 0.03$ & $0.021 \pm 0.04$ \\
2 years & $0.022 \pm 0.03$ & $0.022 \pm 0.03$ & $0.020 \pm 0.03$ \\
3 years & $0.022 \pm 0.03$ & $0.023 \pm 0.02$ & $0.021 \pm 0.04$ \\
\hline
\end{tabular}

Each results is obtained as a mean value from three bottles (three replicates from each bottle) 
Table 4. Reference values for trace elements and $\mathrm{MeHg}$ mass fractions and their expanded uncertainty $(k=2)$ in IAEA-452 biota sample

\begin{tabular}{llll}
\hline Element & $\begin{array}{l}\text { Reference } \\
\text { value }^{\mathrm{a}} \\
\mathrm{mg} \mathrm{kg}^{-1}\end{array}$ & $\begin{array}{l}\text { Expanded } \\
\text { uncertainty } \\
\mathrm{mg} \mathrm{kg}^{-1}\end{array}$ & $\begin{array}{l}\text { Number } \\
\text { of accepted } \\
\text { datasets }\end{array}$ \\
\hline $\mathrm{As}$ & 17.9 & 1.1 & 11 \\
$\mathrm{Cd}$ & 30.5 & 1.6 & 15 \\
$\mathrm{Cr}$ & 5.2 & 0.7 & 8 \\
$\mathrm{Cu}$ & 11.0 & 0.8 & 11 \\
$\mathrm{Fe}$ & 1.068 & 47 & 9 \\
$\mathrm{Hg}$ & 0.16 & 0.02 & 10 \\
$\mathrm{Mn}$ & 279 & 14 & 7 \\
$\mathrm{~Pb}$ & 2.4 & 0.3 & 11 \\
$\mathrm{Zn}$ & 167 & 10 & 13 \\
$\mathrm{MeHg}$ & 0.022 & 0.004 & 16 \\
\hline
\end{tabular}

Informative value for $\mathrm{Ni}$ is $(2.5 \pm 0.3) \mathrm{mg} \mathrm{kg}^{-1}(\mathrm{n}=3)$

${ }^{a}$ The value is the median of accepted sets of data, each set being obtained by different laboratory. The certified values are reported on dry mass basis and are traceable to the SI

${ }^{\mathrm{b}}$ Expanded uncertainty with a coverage factor $k=2$ according to the guide to the expression of uncertainty of measurement (GUM), corresponding to the level of confidence of about $95 \%$ 
Table 5. Methods for determination of $\mathrm{MeHg}$, used by the laboratories participating in IAEA452 worldwide inter-laboratory comparison

\begin{tabular}{lll}
\hline Sample preparation & Detection & $\begin{array}{l}\text { Number } \\
\text { of laboratories }\end{array}$ \\
\hline $\begin{array}{l}\text { Alkaline digestion aqueous phase ethylation }\left(\mathrm{NaBEt}_{4}\right) \text {, GC separation, } \\
\text { thermal desorption of } \mathrm{Hg} \text { species at } 600^{\circ} \mathrm{C}\end{array}$ & AFS & 7 \\
$\begin{array}{l}\text { Alkaline digestion, solvent extraction, derivatisation }\left(\mathrm{NaBEt}_{4}\right), \mathrm{GC} \text { separation } \\
\text { Alkaline digestion, solvent extraction, derivatisation }\left(\mathrm{NaBEt}_{4}\right) \text {, GC separation }\end{array}$ & ICP-MS & 1 \\
Distillation-aqueous phase ethylation $\left(\mathrm{NaBEt}_{4}\right), \mathrm{GC}$ separation & ID-ICP-MS & 1 \\
Alkaline digestion, separation by HPLC & ID-ICP-MS & 1 \\
Dithizone-toluene extraction, GC separation & AFS & 1 \\
Distillation, $\mathrm{BrCl}$ oxidation & GC-ECD & 1 \\
Toluene Extraction, L-cysteine back-extraction & CV-AAS & 1 \\
Leaching $10 \mathrm{~N} \mathrm{HCl}$ & CV-AFS & 1 \\
$\mathrm{H}_{2} \mathrm{SO}_{4} / \mathrm{CuSO} \mathrm{K}_{4} / \mathrm{KBr}$ leaching followed by Toluene extraction, back-extraction & CV-AAS & 1 \\
in aqueous thiosulfate solution & Solid AAS & 1 \\
\hline
\end{tabular}

AFS atomic fluorescence spectrometry, CV-AAS cold vapour atomic absorption spectrometry, Solid AAS solid mercury analyser, ICP-AES inductively coupled plasma atomic emission spectrometry, CV-AFS cold vapour atomic fluorescence spectrometry, ICPMS inductively coupled plasma mass spectrometry, ID-ICP-MS isotope dilution inductively coupled plasma mass spectrometry, GCECD gas chromatography with electron capture detector 


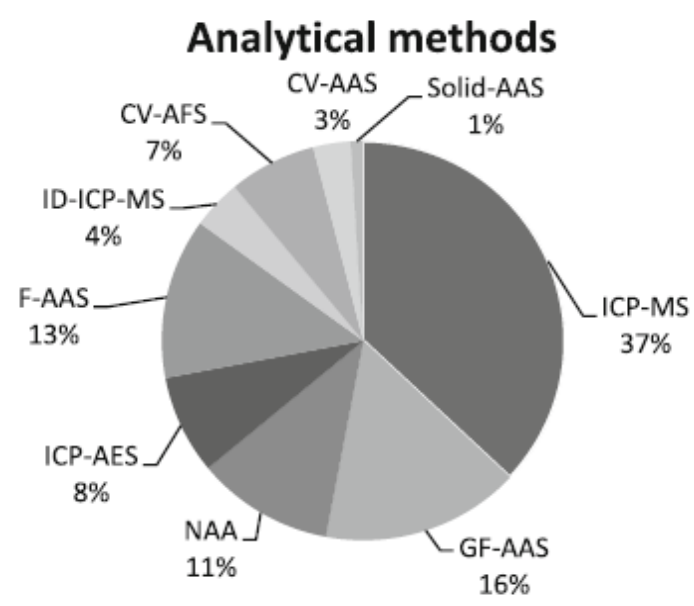

Figure 1. Distribution of measurement results related to analytical methods for the certification of IAEA-452 biota sample 


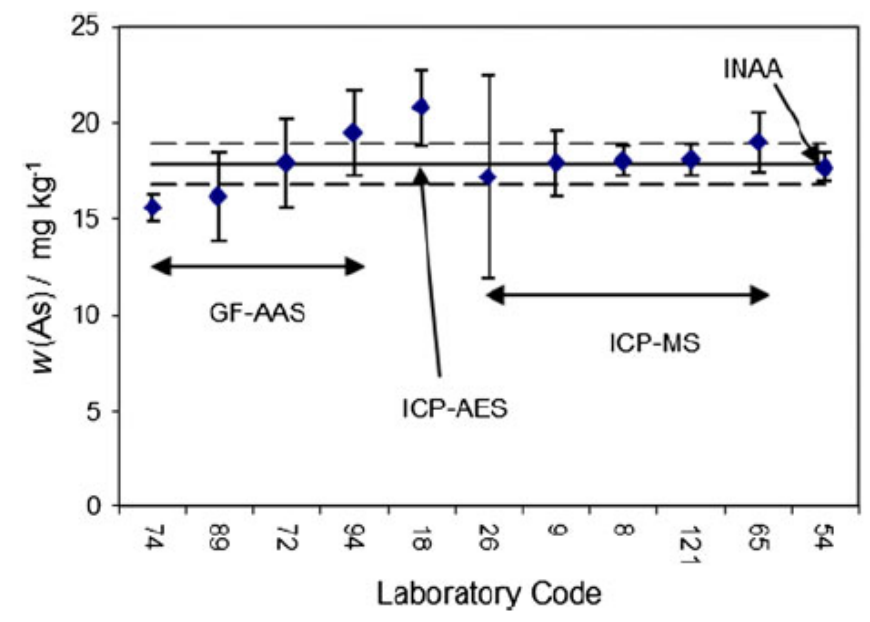

Figure 2. Laboratory results for arsenic mass fraction $\left(\mathrm{mg} \mathrm{kg}^{-1}\right)$ in IAEA-452 biota sample. The median (solid line) and corresponding expanded uncertainty $(k=2)$ (dashed line) are shown. The error bars correspond to the expanded uncertainty reported by each laboratory 


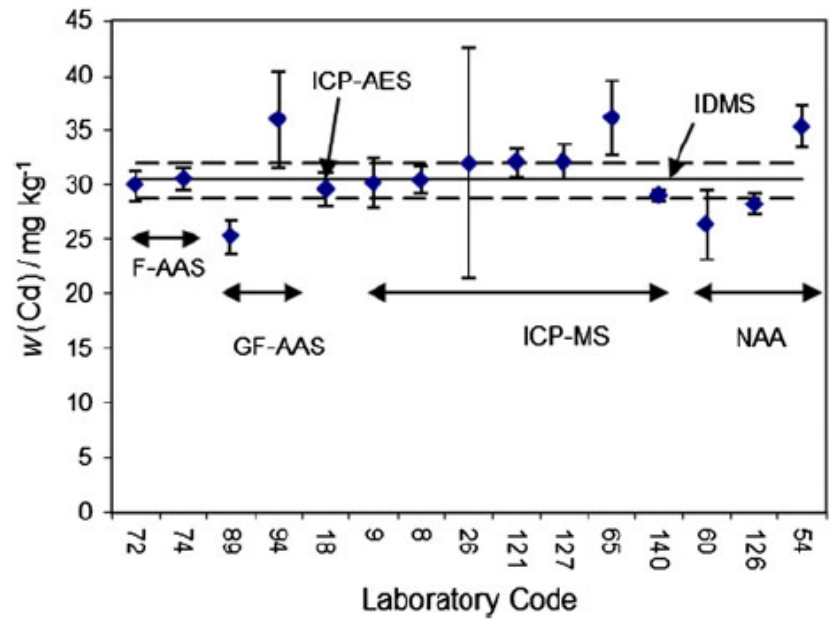

Figure 3. Laboratory results for cadmium mass fraction $\left(\mathrm{mg} \mathrm{kg}^{-1}\right)$ for Cd in IAEA-452 biota sample. The median (solid line) and corresponding expanded uncertainty $(=2)$ (dashed line) are shown. The error bars correspond to the expanded uncertainty reported by each laboratory 


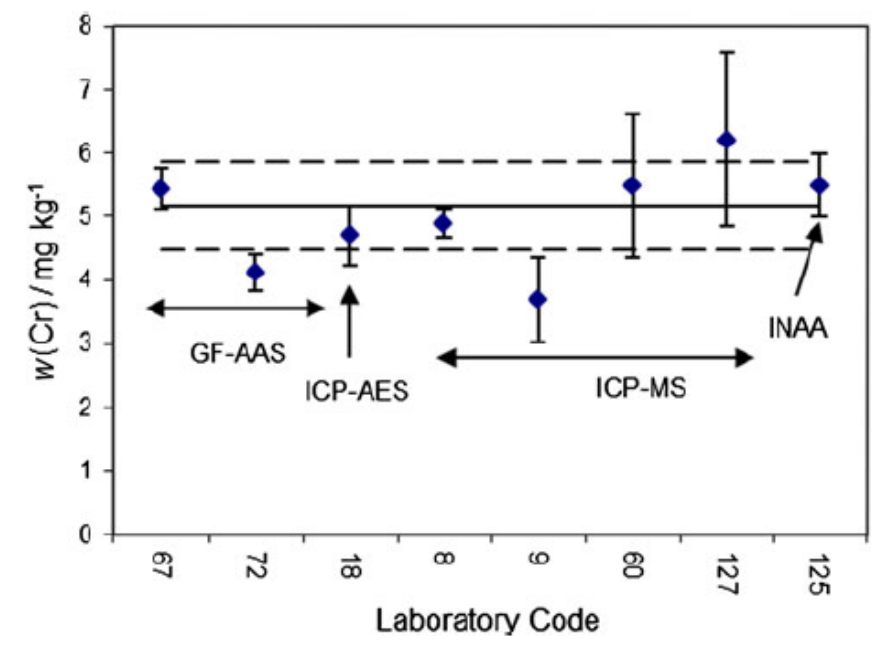

Figure 4. Laboratory results for chromium mass fraction $\left(\mathrm{mg} \mathrm{kg}^{-1}\right)$ in IAEA-452 biota sample. The median (solid line) and corresponding expanded uncertainty $(k=2)$ (dashed line) are shown. The error bars correspond to the expanded uncertainty reported by each laboratory 


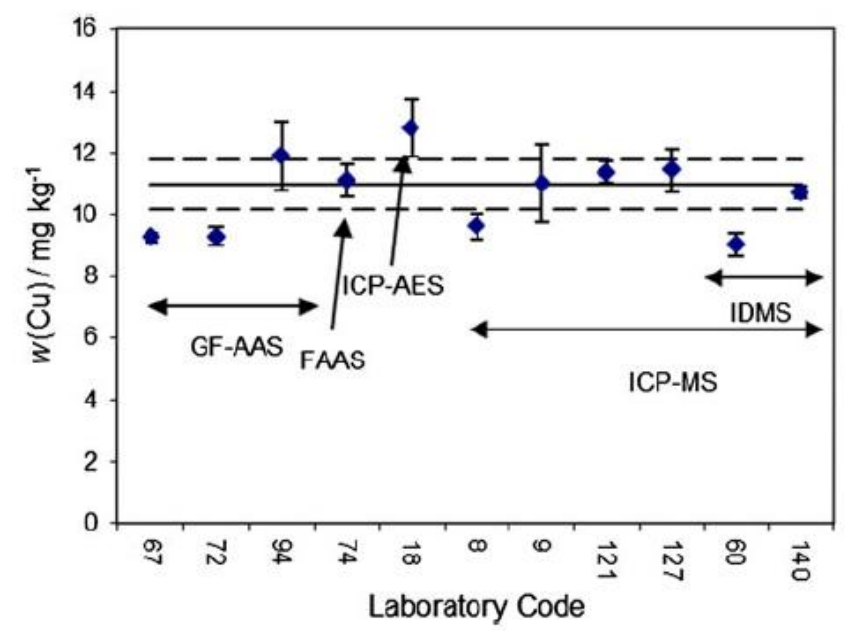

Figure 5. Laboratory results for copper mass fraction $\left(\mathrm{mg} \mathrm{kg}^{-1}\right)$ in IAEA-452 biota sample. The median (solid line) and corresponding expanded uncertainty $(k=2)$ (dashed line) are shown. The error bars correspond to the expanded uncertainty reported by each laboratory 


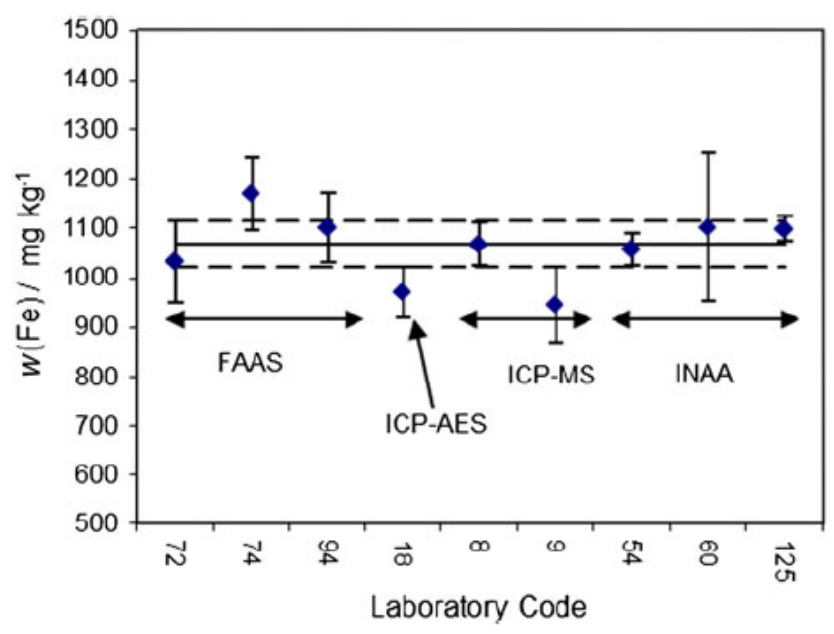

Figure 6. Laboratory results for iron mass fraction $\left(\mathrm{mg} \mathrm{kg}^{-1}\right)$ in IAEA-452 biota sample. The median (solid line) and corresponding expanded uncertainty $(k=2)$ (dashed line) are shown. The error bars correspond to the expanded uncertainty reported by each laboratory 


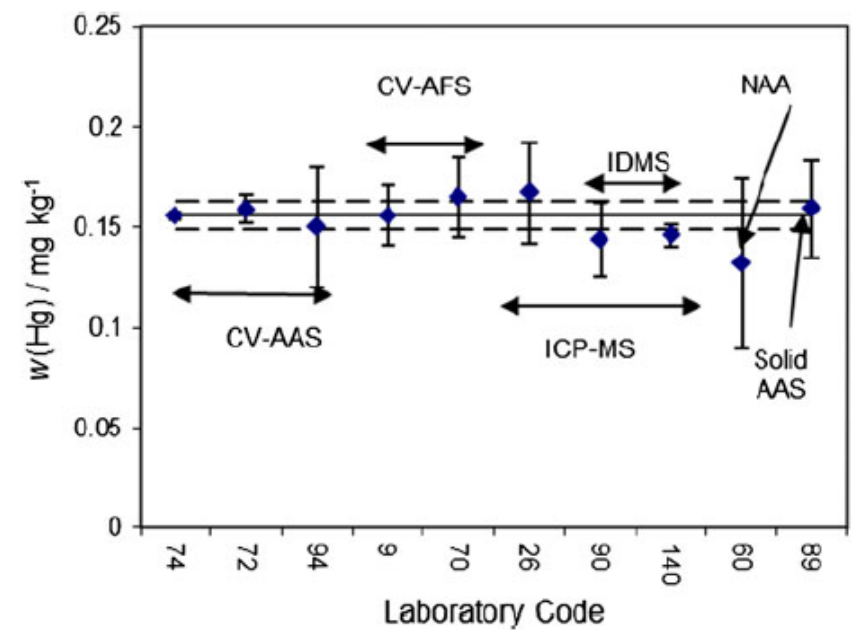

Figure 7. Laboratory results for mercury mass fraction $\left(\mathrm{mg} \mathrm{kg}^{-1}\right)$ in IAEA-452 biota sample. The median (solid line) and corresponding expanded uncertainty $(k=2)$ (dashed line) are shown. The error bars correspond to the expanded uncertainty reported by each laboratory 


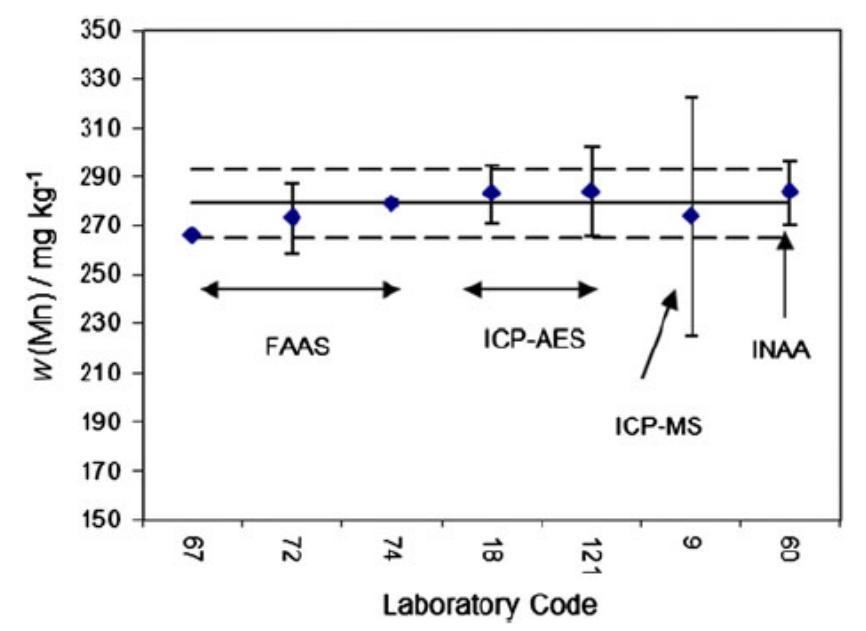

Figure 8. Laboratory results for manganese mass fraction $\left(\mathrm{mg} \mathrm{kg}^{-1}\right)$ in IAEA-452 biota sample. The median (solid line) and corresponding expanded uncertainty $(k=2)$ (dashed line) are shown. The error bars correspond to the expanded uncertainty reported by each laboratory 


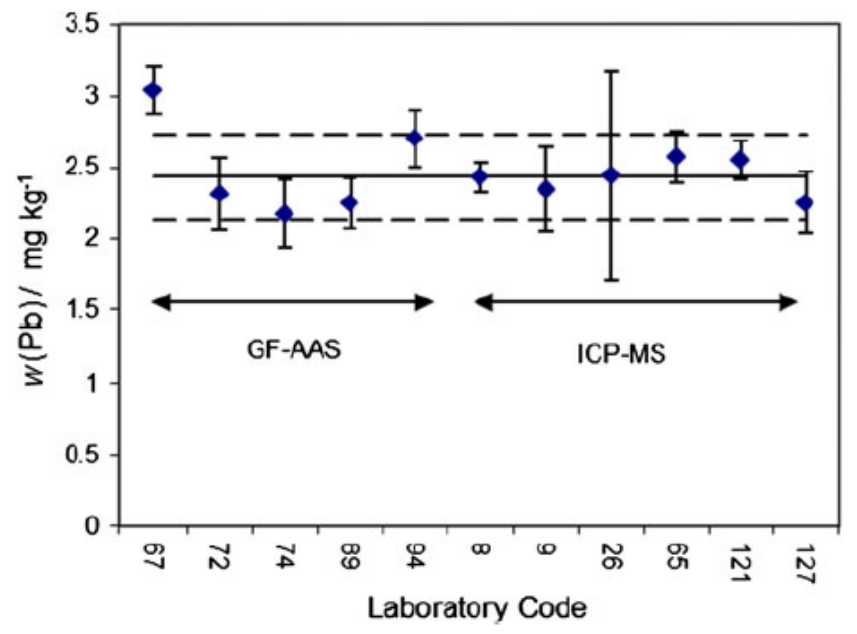

Figure 9. Laboratory results for lead mass fraction $\left(\mathrm{mg} \mathrm{kg}^{-1}\right)$ for $\mathrm{Pb}$ in IAEA-452 biota sample. The median (solid line) and corresponding expanded uncertainty $(k=2)$ (dashed line) are shown. The error bars correspond to the expanded uncertainty reported by each laboratory 


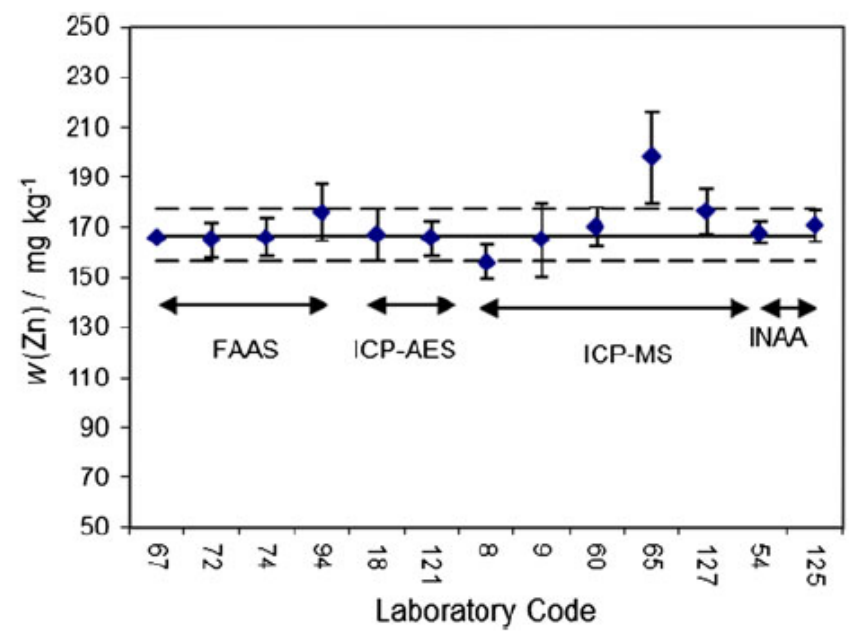

Figure 10. Laboratory results for zinc mass fraction $\left(\mathrm{mg} \mathrm{kg}^{-1}\right)$ in IAEA-452 biota sample. The median (solid line) and corresponding expanded uncertainty $(k=2)$ (dashed line) are shown. The error bars correspond to the expanded uncertainty reported by each laboratory 


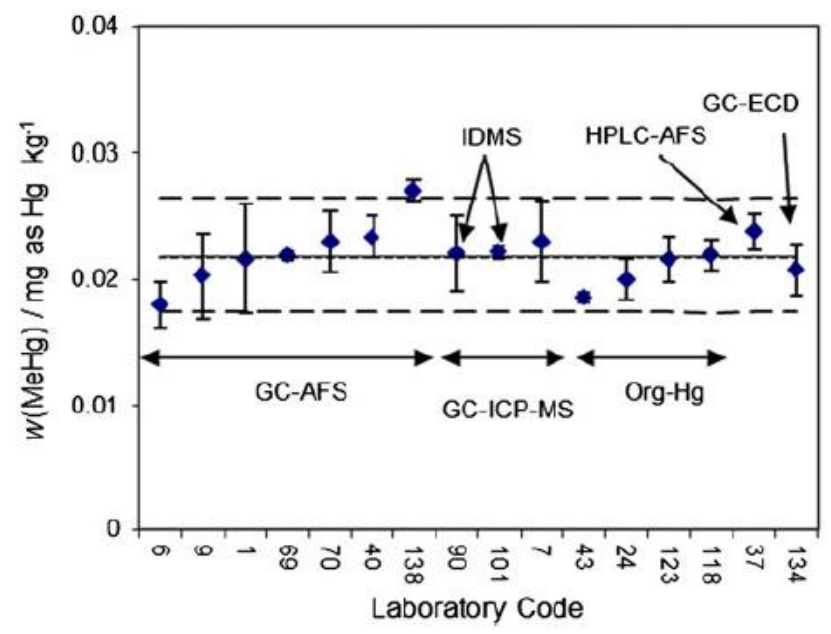

Figure 11. Laboratory results for methyl mercury mass fraction $\left(\mathrm{mg} \mathrm{kg}^{-1}\right)$ in IAEA-452 biota sample. The median (solid line) and corresponding expanded uncertainty $(\mathrm{I}=2)$ (dashed line) are shown. The error bars correspond to the expanded uncertainty reported by each laboratory 


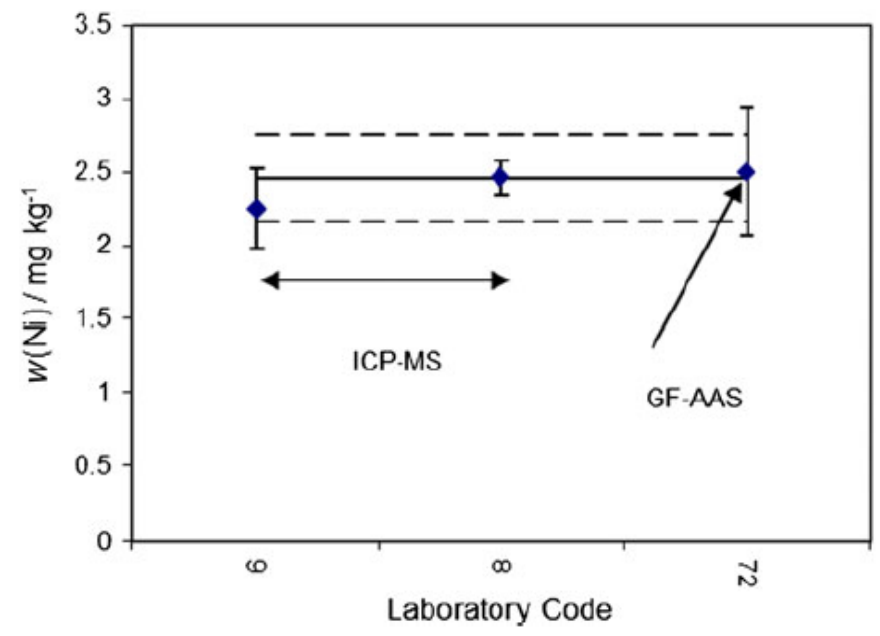

Figure 12. Laboratory results for nickel mass fraction $\left(\mathrm{mg} \mathrm{kg}^{-1}\right)$ in IAEA-452 biota sample. The median (solid line) and corresponding expanded uncertainty $(k=2)$ (dashed line) are shown. The error bars correspond to the expanded uncertainty reported by each laboratory 